\title{
A PANDEMIA DO COVID-19 E AS REPERCUSSÕES PARA A SAÚDE DO TRABALHADOR DO SETOR SAÚDE
}

\section{THE COVID-19 PANDEMIC AND THE REPERCUSSIONS FOR HEALTH WORKERS IN THE HEALTH SECTOR}

\section{Ronan dos Santos ${ }^{1} *$ Mônica Oliveira da Silva e Souza ${ }^{2} *$ Joanir Pereira Passos $^{3}$}

O Painel do Coronavírus da Organização Mundial de Saúde do dia 21 de maio de 2021 apontou que globalmente se tem 166.814.851 casos confirmados, sendo estes responsáveis por 3.458.905 mortes. Estes dados crescentes caracterizam a COVID-19, doença causada pelo novo coronavírus (SARS-CoV-2) como uma crise humanitária, com alta transmissibilidade e letalidade. É neste cenário que atuam ativamente os profissionais de saúde. ${ }^{(1)}$

Entretanto, embora no Brasil, o Sistema Único de Saúde (SUS), considerado o maior sistema público do mundo, seu sucateamento traz alguns entraves que dificultam as ações necessárias para o enfrentamento em situações de crises como a COVID-19. Como reflexos pode-se abalizar a escassez de recursos humanos, deficiência de capacitação dos profissionais para atuarem em situações de crises sanitárias, além da carência de equipamentos médicos hospitalares e insumos, destacando-se os equipamentos de proteção individuais (EPIs). ${ }^{(2)}$

Em março deste ano, a FIOCRUZ realizou uma pesquisa cujo objetivo foi analisar o impacto da pandemia de COVID- 19 entre os profissionais de saúde, levando em consideração o ambiente e a jornada de trabalho, o vínculo com a instituição onde trabalhavam, a vida do profissional na prépandemia e as consequências do atual processo de trabalho envolvendo aspectos físicos, emocionais e psíquicos desse grupo de profissionais. ${ }^{(3)}$

Os dados indicaram que $43,2 \%$ dos profissionais de saúde não se sentem protegidos no trabalho de enfrentamento da COVID-19, o principal motivo para $23 \%$ está relacionado à falta, à escassez e à inadequação do uso de EPIs (64\% revelaram a necessidade de improvisar

\footnotetext{
${ }^{1}$ Enfermeiro da Educação continuada do Hospital do Câncer I/INCA, Membro Técnico no Grupo de Pesquisa do Laboratório de Pesquisa: Enfermagem, Tecnologias, Saúde e Trabalho e aluno do Curso de Doutorado do Programa de Pós-Graduação em Enfermagem e Biociências (PPGENFBIO) do Centro de Ciências Biológicas e da Saúde (CCBS), da Universidade Federal do Estado do Rio de Janeiro (UNIRIO). Orcid: : https://orcid.org/0000-0002-1296-3328 - Email: ronan.santos@inca.gov.br

${ }^{2}$ Enfermeira, professora na Escola de Formação em Saúde Enfermeira Izabel dos Santos (SES/RJ), Membro Técnico no Grupo de Pesquisa do Laboratório de Pesquisa: Enfermagem, Tecnologias, Saúde e Trabalho e aluna do Curso de Doutorado do Programa de Pós-Graduação em Enfermagem e Biociências (PPGENFBIO) do Centro de Ciências Biológicas e da Saúde (CCBS), da Universidade Federal do Estado do Rio de Janeiro (UNIRIO). Orcid: https://orcid.org/0000-0002-3657-8651 - Email: monsouza1997@gmail.com

${ }^{3}$ Professor Titular do Departamento de Enfermagem de Saúde Pública, líder do Laboratório de Pesquisa: Enfermagem, Tecnologias, Saúde e Trabalho. Atualmente, exerce a Coordenação do Curso de Doutorado do Programa de Pós-Graduação em Enfermagem e Biociências, da Universidade Federal do Estado do Rio de Janeiro (UNIRIO) - Orcid: https://orcid.org/0000-0002-6880-4545 Email: joppassos@hotmail.com
} 
equipamentos). Os participantes da pesquisa também relataram o medo generalizado de se contaminar no trabalho (18\%), a ausência de estrutura adequada para realização da atividade (15\%), além de fluxos de internação ineficientes $(12,3 \%)$. O despreparo técnico dos profissionais para atuar na pandemia foi citado por $11,8 \%$, enquanto $10,4 \%$ denunciaram a insensibilidade de gestores para suas necessidades profissionais. ${ }^{(3)}$

Entende-se que não obstante, a pandemia ainda se estenderá por algum tempo. Os desafios para os trabalhadores da saúde no exercício de suas atividades laborais durante esse período ainda serão a elevada transmissibilidade do vírus, a sobrecarga de trabalho, a escassez de equipamentos e insumos hospitalares e os impactos na saúde mental.

Deste modo, considera-se importante refletir sobre os fatores que afetam diretamente a saúde destes trabalhadores durante o desenvolvimento de suas atividades laborais, dado que desempenham um papel fundamental em todas as etapas do ciclo prevenção-tratamento-reabilitação que envolve a pandemia do COVID-19.

1. World Health Organization. Coronavirus (COVID-19) Dashboard. [Internet]. Globally, as of 2:50pm CEST, 24 May 2021 [cited 2021 may. 24]. Available from: https://covid19.who.int/

2. Editorial. COVID-19: protecting health-care workers. The Lancet [Internet]. 2020 [cited 2021 may. 24]; Mar 21;395(10228):922. Available from: https://www.thelancet.com/journals/lancet/article/PIIS0140-6736(20)30644-9/fulltext doi: 10.1016/S0140-6736(20)30644-9.

3. Leonel F. Pesquisa analisa o impacto da pandemia entre profissionais de saúde. Fundação Oswaldo Cruz [Internet] 22 mar.2021 [citado 2021 maio 24]. Disponível em: https://portal.fiocruz.br/noticia/pesquisa-analisa-o-impacto-da-pandemia-entreprofissionais-de-saude 